\title{
The Effect of Elderly Gymnastics on Menopausal Women on Decreased Body Fat
}

\author{
Sri Mulyati ${ }^{1}$, Novita Rina Antarsih ${ }^{2}$, Karningsih ${ }^{3}$, Dewi Nirmalasari ${ }^{4}$ \\ 1,2,3,4 Midwifery Department of Health Polytechnic of Ministry of Health Jakarta III, \\ Bekasi, Indonesia \\ Email: mulyati.atmaja@yahoo.com
}

\begin{abstract}
Decreased body fat is an important thing to do in menopausal women whose estrogen levels decrease with the addition of age. One way to lose body fat is elderly gymnastics. The elderly gymnastics movement has evolved a lot but no senior gymnastics has focused on body fat loss. The aim of this study is to find out the effect of elderly gymnastics modification on the decrease in body fat in menopausal women. Method of this research is quasi-experimental, in 35 menopausal women given modified elderly gymnastics focused on the reduction of body fat, while 35 respondents with standard senior gymnastics. This study with a frequency of $1 \mathrm{x} /$ week for 3 months. After doing senior gymnastics modification 12 times for 3 months, there was an average difference in the percentage of total body fat menopause in all four measurements between groups of $5.5 \%$, elderly gymnastics modification as well as elderly gymnastics older version maintains the stability of visceral fat percentage in menopausal women, a decrease in abdominal fat thickness of $1.1 \mathrm{~mm}$ with an average difference between the 3rd and 4th measurements by $7.6 \%$. Abdominal circumference in menopausal women decreased in the treatment group by $1 \mathrm{~cm}$, while in the control group experienced an increase of $0.3 \mathrm{~cm}$ after 3 months of treatment. In the treatment group, there was a decrease in triglyceride levels after treatment compared to the control group. Elderly gymnastic modification can decrease body fat gradually after the 2nd month (8th week) intervention in menopausal women.
\end{abstract}

Keywords: Elderly Gymnastics, Fat, Menopause, Triglycerides.

\section{A. INTRODUCTION}

In the Millennium Development goals (MDGs) the era of disease attention focuses on non-communicable diseases (NCDs), particularly in low and middleincome countries. In 2016, NCDs accounted for $71 \%$ of all global deaths, and $85 \%$ of the 15 million premature deaths (deaths between ages 30 and 70) occurred in lowand middle-income countries. In the event of a health emergency such as COVID-19, patients with pre-existing NCD conditions such as hypertension and diabetes, become more vulnerable and at higher risk of dying. Therefore prevention of NCD risk factors such as obesity, mental health conditions, in the first place is very important [1].

Aging involves changes in body composition, one of which is the decrease in muscle mass and increased fat mass [2]. In elderly, being obesity is associated with high cardiovascular prevalence, metabolic diseases, cancer, many other medical conditions such as increased functional limitations, disabilities, and poorer quality of life, and it is associated with all causes of death [3]. Obesity is characterized by excess storage of fat in muscles and adipose tissues [4]. Obesity in elderly especially central obesity is more common in women especially central obesity is associated 
with a decrease in the hormone estrogen [5]. The increases in overweight and obesity in menopausal women are important public health concerns [6].

Handling obesity includes healthy lifestyle changes such as nutrition, physical activity, and behavioral therapy [7]. Elderly gymnastics is low impact aerobic gymnastics with light to moderate intensity, short duration with easy movement does not pose a risk of injury, does not stop, and rarely changes movements suddenly. This gymnastics is performed with a low frequency of implementation. [8]. Elderly mobility, including the weak, can be improved through regular physical activity to reduce morbidity and death from chronic diseases. Level of fitness of elderly need to be evaluate before determining their level of effort for physical activity [9]. The human body can act as a fat-burning machine by depending on lowcalorie foods instead of high-calorie foods in addition to doing regular exercise, avoiding toxins and processed food, and applying any fat flush dietary program under the approval of a professional doctor [10].

Elderly gymnastics has been done with various versions of the movement, but to date, the prevalence of obesity including central obesity is increasing. Therefore, we have modified the elderly gymnastics movement which is more focused on lowering body fat, especially in women who start early after menopause.

\section{B. METHODS}

This research is a quantitative research using a quasi-experiment with the design of a non-randomized control group pre-test post-test. Independent variable modified elderly gymnastics, the dependent variable of body fat mass (Percentage of body fat, Percentage of visceral fat, Abdominal fat thickness), Abdominal Circumference, and Triglycerides. Research conducted from June until November 2019. The number of samples from each group was 35 menopausal women with purposive sampling techniques and criteria of inclusion of Menopausal women, residing in the research area, and have no history of diabetes mellitus. The analysis used General Linear Measures Repeated (GLMr) for total body fat percentage data, visceral fat percentage, the thickness of abdominal fat, size of the abdominal circumference. In triglyceride level data conducted independent statistical test sample t-test.

\section{RESULTS AND DISCUSSION}

The characteristics of the respondents in this study can be seen in table 1 below:

Table 1. Characteristics of Respondents

\begin{tabular}{|c|c|c|c|c|c|c|c|c|}
\hline & \multicolumn{4}{|c|}{ Treatment Group $(n=35)$} & \multicolumn{4}{|c|}{ Control Group $(n=35)$} \\
\hline & $\begin{array}{l}\text { Mean } \\
( \pm \text { SE })\end{array}$ & $\begin{array}{c}\text { Range } \\
\text { (Min-Max) }\end{array}$ & $\mathrm{Sd}$ & $\begin{array}{c}\mathrm{f} \\
(\%)\end{array}$ & Mean $( \pm$ SE) & $\begin{array}{c}\text { Range } \\
\text { (Min-Max) }\end{array}$ & Sd & $f(\%)$ \\
\hline Age (Year) & $57,86(0,872)$ & $20(50-70)$ & 5,157 & - & $69,17(1,050)$ & $24(60-84)$ & 6,214 & - \\
\hline Occupation & & & & & & & & \\
\hline Housewife & - & - & - & 82,9 & & & & 97,1 \\
\hline Employed & & & & 17,1 & & & & 2,9 \\
\hline
\end{tabular}




\begin{tabular}{|c|c|c|c|}
\hline \multicolumn{4}{|l|}{ Marital Status } \\
\hline Widow & & 22,9 & 37,1 \\
\hline Married & & 77,1 & 62,9 \\
\hline \multicolumn{4}{|l|}{ Education } \\
\hline $\begin{array}{l}\text { Primary } \\
\text { School }\end{array}$ & - & 2,9 & 2,9 \\
\hline $\begin{array}{l}\text { Junior High } \\
\text { School }\end{array}$ & - & 37,1 & 17,1 \\
\hline $\begin{array}{l}\text { Senior High } \\
\text { School }\end{array}$ & & 51,4 & 60 \\
\hline College & & 8,6 & 20 \\
\hline
\end{tabular}

The sample in this study was on average 63.51 years old, $90 \%$ did not work only to take care of household needs such as cooking, taking care of grandchildren or active in teaching and gymnastics activities and 55.7\% were high school educated. In the treatment group and control group there were no average differences in education level, control status, and sample work in both groups, but what was lacking in this study was that there were average age differences in control and intervention groups. This cannot be controlled because the availability of samples to participate in this study is so limited that it cannot accurately age the intervention and control groups.

In the intervention and control treatment group, there was no difference in employment status, marital status, and level of education.

Table 1 Within Subject \% Total Body Fat

\begin{tabular}{|c|c|c|c|c|}
\hline & & & Sig & $\begin{array}{c}\text { Partial } \\
\text { Eta } \\
\text { Squared }\end{array}$ \\
\hline \multirow{2}{*}{ Within Subject Effect } & $\%$ Total Fat & & 0,02 & 0,050 \\
\hline & $\%$ total body fat * Group & & 0,013 & 0,055 \\
\hline \multirow{6}{*}{ Within Subject Contrast } & $\%$ Total Fat & P1 Vs P2 & 0,86 & 0,000 \\
\hline & & P2 Vs P3 & 0,54 & 0,005 \\
\hline & & P3 Vs P4 & 0,01 & 0,084 \\
\hline & $\%$ total body fat * Group & P1 Vs P2 & 0,70 & 0,002 \\
\hline & & P2 Vs P3 & 0,77 & 0,001 \\
\hline & & P3 Vs P4 & 0,01 & 0,094 \\
\hline
\end{tabular}

Based on the Green House-Geisser test, there was a difference in the average percentage of total body fat between the four measurements of $5 \%$ and the average difference in the percentage of total body fat of menopause women in all four measurements between groups of $5.5 \%$. In the 3rd and 4 th measurements, there was a difference in the average percentage of total body fat of menopausal women by $8.4 \%$. 


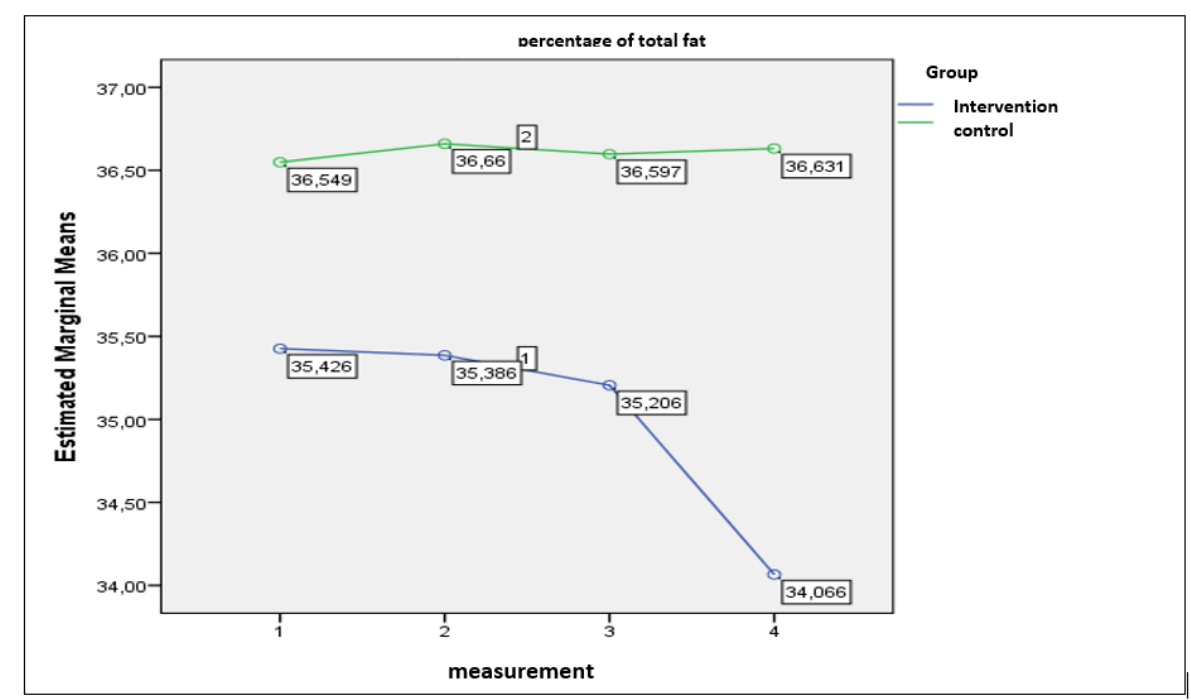

Figure 1. Plot Average \% Total Body Fat

From the figure 1, it was seen that elderly gymnastic modification began to cause a \% decrease in total body fat in menopausal women after 3 months of intervention (P4) and its gradual and gradual decline, while in the control group it tended to increase.

Table 3. Within Subject \% Visceral Fat

\begin{tabular}{ccccc}
\hline & & & \multicolumn{2}{c}{$\begin{array}{c}\text { Partial } \\
\text { Eta } \\
\text { Squared }\end{array}$} \\
\hline \multirow{2}{*}{ Within Subject Effect } & & Sig & 0,658 \\
\cline { 2 - 5 } & & \% Visceral Fat & & 0,007 \\
\cline { 2 - 5 } Within Subject Contrast & \% Visceral Fat * Group & & 0,953 & 0,001 \\
\cline { 2 - 5 } & \% Visceral Fat & P1 Vs P2 & 0,78 & 0,001 \\
\cline { 2 - 5 } & & P2 Vs P3 & 0,64 & 0,003 \\
\cline { 2 - 5 } & & P3 Vs P4 & 0,41 & 0,010 \\
\cline { 2 - 5 } & & P1 Vs P2 & 0,78 & 0,001 \\
\cline { 2 - 5 } & & P2 Vs P3 & 1,00 & 0,000 \\
\cline { 2 - 5 } & & P3 Vs P4 & 0,78 & 0,001 \\
\hline
\end{tabular}




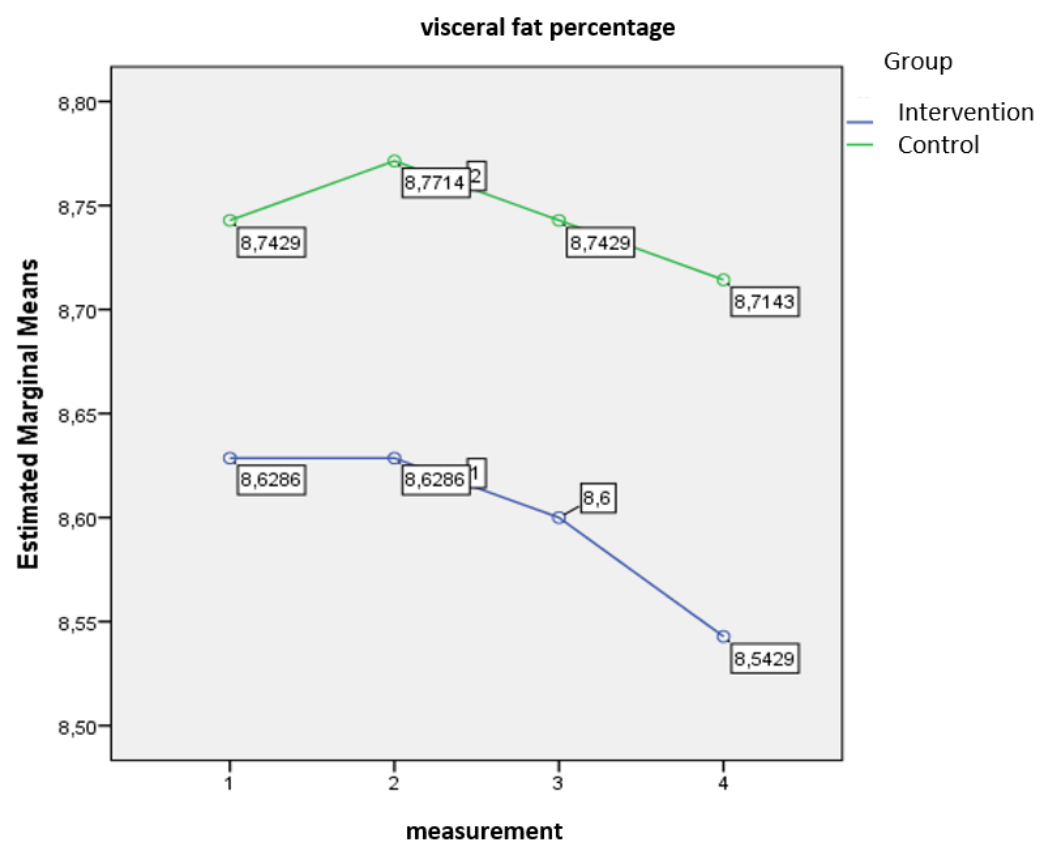

Figure 2. Plot Average \% Visceral Fat

From the results of the analysis obtained that both modified senior gymnastics and standard elderly gymnastics (e.g. version SJK 2014) the same began to decrease visceral fat after the implementation of senior gymnastics for 2 months (P3) and in the treatment group after 3 months of intervention (P4) the average decrease in visceral fat was greater than the control group.

Table 4. Within Thickness of Belly Fat

\begin{tabular}{|c|c|c|c|c|}
\hline & & & Sig & Partial Eta Squared \\
\hline \multirow{2}{*}{ Within Subject Effect } & Thickness of belly fat & & 0,059 & 0,039 \\
\hline & Thickness of belly fat * group & & 0,893 & 0,003 \\
\hline \multirow{6}{*}{ Within Subject Contrast } & Thickness of belly fat & P1 Vs P2 & 0,62 & 0,004 \\
\hline & & P2 Vs P3 & 0,79 & 0,001 \\
\hline & & P3 Vs P4 & 0,02 & 0,076 \\
\hline & Thickness of belly fat ${ }^{*}$ group & P1 Vs P2 & 0,98 & 0,000 \\
\hline & & P2 Vs P3 & 0,79 & 0,001 \\
\hline & & P3 Vs P4 & 0,57 & 0,005 \\
\hline
\end{tabular}




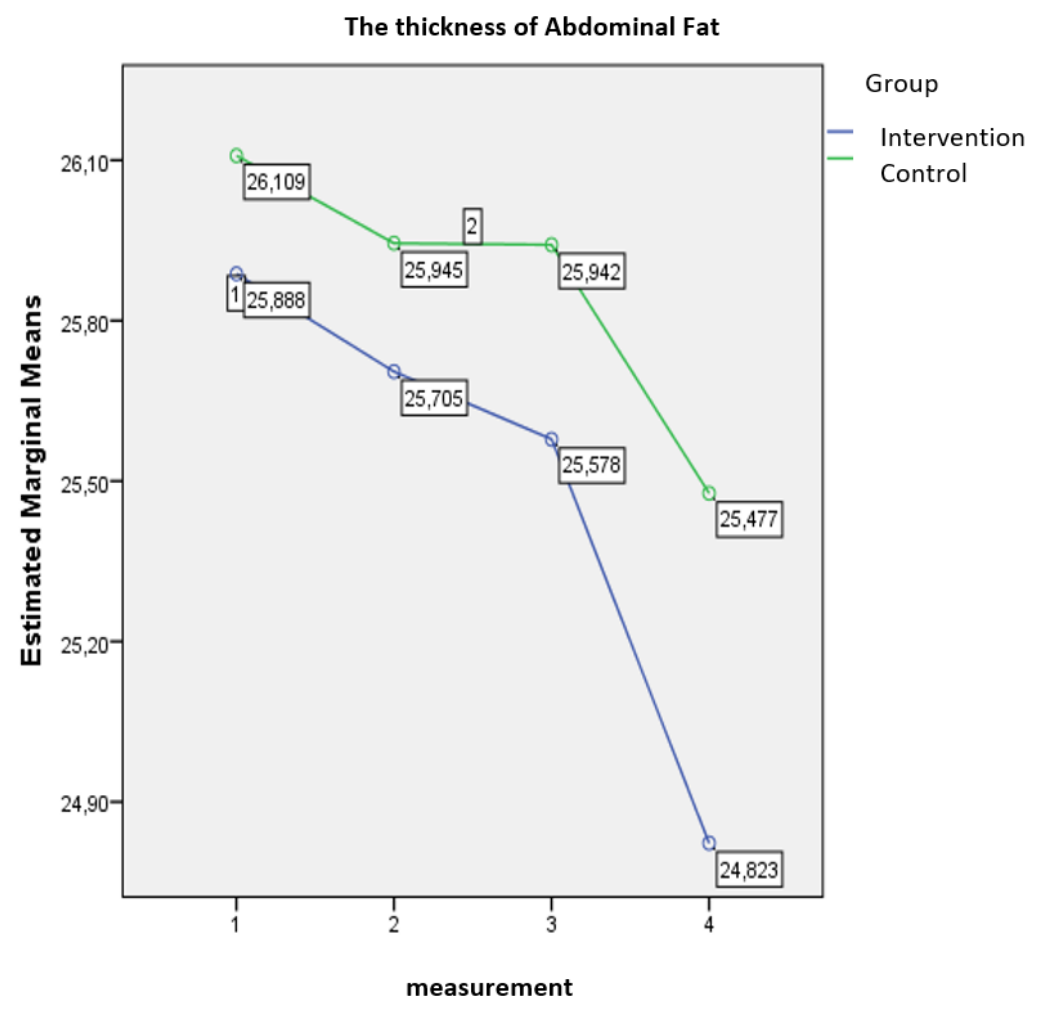

Figure 1. Plot Average Abdominal Fat Thickness

In the 3rd and 4th measurements, there was an average difference in abdominal thickness of $7.6 \%$ in menopause women. In plot 3 , it was seen that there had been a decrease, in the thickness of abdominal fat both in the treatment group and in the control group since one month after intervention until optimal reduction was seen at the time of gymnastics performed after 3 months (P4). However, it was seen that on average a greater decrease occurred in the treatment group than in the control group.

Table 2 Within Size of Abdominal Circumference

\begin{tabular}{|c|c|c|c|c|}
\hline & & & Sig & Partial Eta Squared \\
\hline \multirow{2}{*}{$\begin{array}{l}\text { Within Subject } \\
\text { Effect }\end{array}$} & \multicolumn{2}{|l|}{ Abdominal circumference size } & 0,744 & 0,004 \\
\hline & \multicolumn{2}{|l|}{ Abdominal circumference size * group } & 0,553 & 0,008 \\
\hline \multirow{6}{*}{$\begin{array}{l}\text { Within Subject } \\
\text { Contrast }\end{array}$} & \multirow{3}{*}{ Abdominal circumference size } & P1 Vs P2 & 0,96 & 0,000 \\
\hline & & P2 Vs P3 & 0,97 & 0,000 \\
\hline & & P3 Vs P4 & 0,02 & 0,078 \\
\hline & \multirow{3}{*}{ Abdominal circumference size ${ }^{*}$ group } & P1 Vs P2 & 0,81 & 0,001 \\
\hline & & P2 Vs P3 & 0,74 & 0,002 \\
\hline & & P3 Vs P4 & 0,03 & 0,067 \\
\hline
\end{tabular}




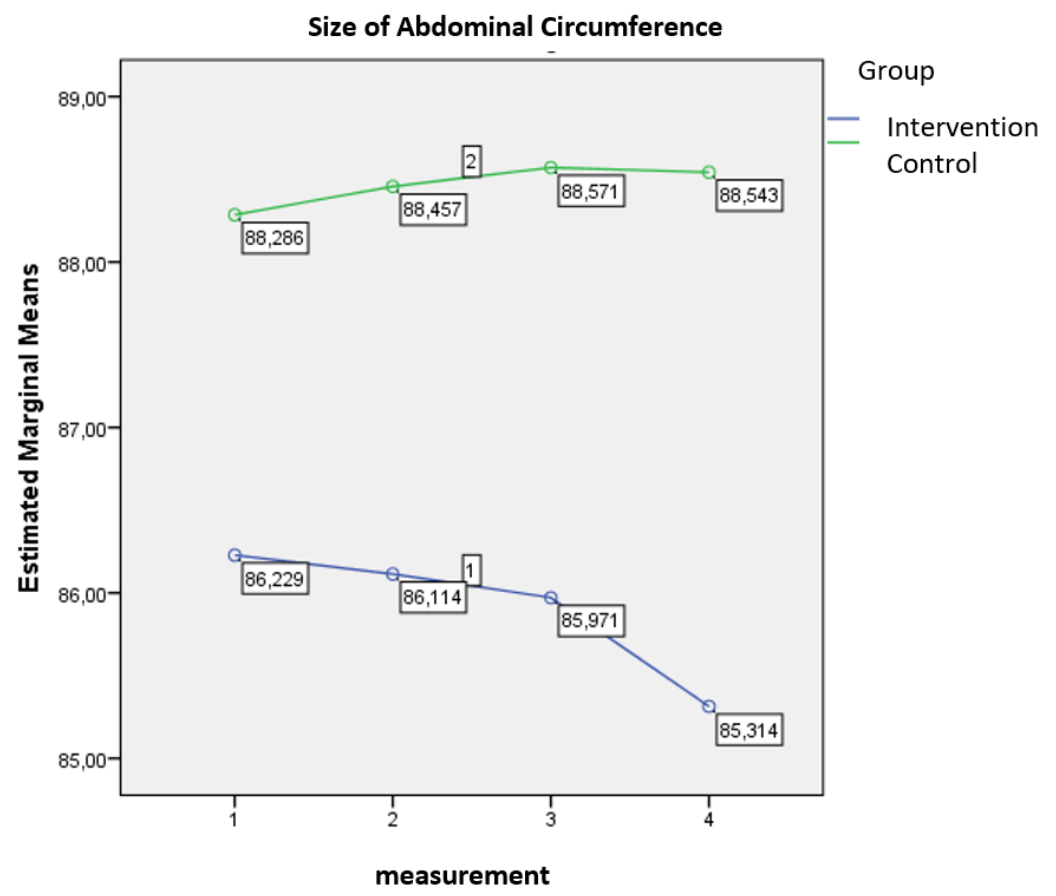

Figure 4. Plot Average Abdominal Circumference Size

The average difference in abdominal circumference occurred in the third and fourth measurements of $7.8 \%$. The average difference in abdominal circumference was $6.7 \%$ in the treatment and control group between the 3rd and 4 th gauges. In figure 4 seen a decrease in the size of the abdominal circumference occurs in the treatment group starting from 1 month after intervention (P2) and optimal after 3 months of intervention (P4).

Table 3 Triglyceride Levels Before and After Intervention

\begin{tabular}{cccccc}
\hline Group & & Mean + SEM & Sd & CI & p \\
\hline \multirow{2}{*}{ Treatment } & Pre Gymnastics & $136,40(+6,09)$ & 36,01 & $-38,75-1,04$ & 0,063 \\
\cline { 2 - 4 } & Post Gymnastics & $134,00(+7,12)$ & 44,39 & $-48,99-(-7,70)$ & \\
\hline \multirow{2}{*}{ Control } & Pre Gymnastics & $155,28(+7,90)$ & 46,71 & $-38,77-1,06$ & 0,008 \\
\cline { 2 - 3 } & Post Gymnastics & $162,34(+7,50)$ & 42,13 & $-48,98-(-7,70)$ & \\
\hline
\end{tabular}

There was an average difference in triglyceride levels after senior gymnastics modifications were performed in the treatment group compared to the control group.

Before menopause, estrogen stores fat in the thighs, hips, and buttocks. During and after menopause, a decrease in estrogen causes an increase in total body fat (TBF) on a but now more so in central portion [6]. There are postmenopausal women estrogen deficiency contributes to obesity because estrogen plays a role in fat storage and distribution of fat [11]. During the menopause transition, women tend to gain weight [7]. The percentage of one's body fat can be assessed from the following:

a. Percentage of total body fat

The basal metabolism of the elderly shows that age tends to increase weight. Lifestyle changes and reduced physical activity lead to weight gain with age. Total peak body fat is about 65-70 years, while in later age it decreases [12], [13].

This percentage of fat is used to determine the optimal composition of a person's body. According to who (1996), elderly women are said to have high body 
fat if more than $35 \%$, while in elderly men more than $25 \%$. In this study, overall from 70 existing samples, the average percentage of total body fat before the research was conducted in menopausal women by $35.98 \%$ with a minimum value of $25.30 \%$ and a maximum of $44.70 \%$.

The results of the study found that the average percentage of total fat in the control and intervention groups was no different. In the intervention group, although statistically there was no significant difference between the measurement times taken every 4 weeks, it was seen that there was a slow decline from the implementation of gymnastics interventions to the next 12 weeks.

Total body fat reduction occurred in the intervention group on the 3rd measurement (post 8 weeks intervention) up to the 4th measurement or 12 weeks of intervention occurred a decrease of $1.14 \%$ from the $3 \mathrm{rd}$ measurement. In the $3 \mathrm{rd}$ and 4th measurements, there was an average difference in total body fat percentage of menopausal women by $8.4 \%$ between treatment and control groups. In the control group, the average percentage of total stable body fat was estimated at approximately $36 \%$ until the last study. The results also showed the difference in the average percentage of total body fat between the four measurements by $5 \%$ and the average difference in the percentage of total body fat in menopausal women in the four measurements between groups of $5.5 \%$.

This indicates that modified elderly gymnastics has the effect of decreasing percentage of total body fat more effectively compared to existing gymnastics. Aerobic exercise with light intensity when done continuously and regularly at least 1 time a week.

b. Visceral Fat Percentage

Aging causes a gradual decrease in body mass (LBM) and affects the distribution of total and regional fat mass (FM). In particular, the amount of fat in the abdominal area, known as visceral adipose tissue (VAT) especially in the elderly is closely related to the risk of cardiovascular disease (CVD) and obesity in general. Physical activity is a marker of obesity in overweight and obese populations [14]. Recent studies confirm that visceral adipose tissue (VAT) is also more responsible for low-level systemic inflammation compared to subcutaneous adipose tissue (SAT). VAT increases with age, in women the increase in visceral fat occurs especially after menopause age [15]. Visceral fat (VF) in adipose tissue stored in the stomach associated with metabolic syndrome. Menopause affects weight gain and changes in the distribution of abdominal fat. As estrogen therapy influences the distribution of abdominal fat in post-menopausal women, so menopause increases VF. In the female sex hormone levels in women overweight different from women of normal-weight during menopause. Sex hormone levels could lead to altered abdominal fat distribution and Metabolic Syndrome components between normalweight and overweight during Menopause. VF tends to age rather than menopause from studies on overweight pre-menopausal and post-menopausal women [16].

Normal visceral fat percentage on a scale of 1-12, if it exceeds 13 then the visceral fat levels in the body exceed normal. The results of the cross-sectional Sofa 
(2018) study stated that the average elderly woman in the working area of Jagir health center, Wonokromo, Surabaya ranged in $9.84 \%$ and showed no relationship between age and visceral fat percentage [17].

The results of prior research on the implementation of interventions in the control and intervention groups, their average visceral fat percentage was $8 \%$ with a minimum value of $2 \%$ and a maximum of $15 \%$. Those who had visceral fat were more than $13 \%$ as much as $7.1 \%$ of the entire study sample and by the end of the study to $5.7 \%$.

The results showed that both old elderly gymnastics and modifications both had a decreased effect of $0.1 \%$ in menopausal women after 12 weeks of intervention. This elderly gymnastics maintains the stability of visceral fat percentage in menopausal women and the decrease is done gradually and sluggishly, not losing visceral fat quickly because it is a low-intensity aerobic gymnastics. If you want to lose body fat, one percentage of body fat quickly then can do aerobic gymnastics with a moderate intensity that can dismantle the fat deposits in the body with the frequency of gymnastics three times a week [18].

c. Thickness of Abdominal Fat (Abdominal Skinfold)

Skin folds are indirectly associated with visceral fat, and the thickness of the folds of the skin folds impacts the endothelial environment. The thickness of the skin folds (ST) is correlated with impaired lipid levels and blood pressure. The skin fold thickness and waist-hip ratio (WHR) makes it possible to determine the central location of corporal fat, whose increase is a cardiovascular risk, and ST positively correlates with the appearance of hypertension. Due to loss of endothelial activity nitric oxide (NO) endothelial dysfunction can precede cardiovascular disease for several years [19].

One way to find out the mass of body fat is to use skinfold caliper measurements. This tool is a tool used to measure the thickness of the skin folds underlying fat folds with measurement results in millimeters. One of the measurement location points is abdominal skin (abdominal part).

In this study, it was found that the average thickness of abdominal fat in the control group was $26,109 \mathrm{~mm}$ and $25,888 \mathrm{~mm}$ in the treatment group. In the treatment group, the test results showed a decrease in size at each stage of measurement (P1 to P4) with the peak occurring at P3 and P4 time of $0.8 \mathrm{~mm}$. The results showed that in the 3rd and 4th measurements, there was an average difference in abdominal thickness by $7.6 \%$.

So the decrease during the 12 weeks of intervention in the treatment group was $1.1 \mathrm{~mm}$. While in the control group, the average thickness of abdominal fat decreased by $12 \mathrm{mg}$ by $0.7 \mathrm{~mm}$. The measurement of abdominal fat thickness is important because it is related to central obesity in addition to the size of the waist circumference. In this study, each measurement was done three times per individual and will be calculated on average. Subcutaneous fat reduction, one of which is the thickness of abdominal fat in addition to the type of gymnastics, duration, and 
intensity of gymnastics, is also closely related to diet and activities in menopausal women.

d. Abdominal Circumference (Waist)

Obesity is a growing global health problem, as it is associated with cardiovascular disease (CVD) associated with visceral adiposity. People over the age of 65 increase in proportion as the prevalence of metabolic syndrome (MS) increases the risk of morbidity and mortality due to metabolic risk factors [20]. Aging is associated with an increase in central and intra-abdominal fat and a decrease in the lower body of subcutaneous fat [7], [11]. Changes in body composition related to this age may occur independent of changes in total adiposity, weight or waist circumference [11]. Excess visceral fat in the stomach is known as central obesity, which causes the stomach to protrude. The measurement of obesity through waist circumference (WC) has been established as a simple and practical method for the diagnosis of central obesity that is routinely applied as part of physical examinations in clinical practice. WC consists of subcutaneous and visceral fat, visceral fat much more closely related to MS than subcutaneous fat [20].

The average abdominal circumference size in menopausal women in the intervention group was $86.23 \mathrm{~cm}$ and in the control group was $88.28 \mathrm{~cm}$. The results of sofa research (2018) stated that the average abdominal circumference in elderly women in the working area of Jagir health center, Wonokromo, Surabaya amounted to $88.83 \mathrm{~cm}$ [17].

In the 3rd and 4th measurements, the results of this study showed that there was a difference in the average abdominal circumference of menopausal women by $7.8 \%$ with an average difference in abdominal circumference of $6.7 \%$ in the treatment and control group. The study stated that in the treatment group that received modified elderly gymnastics for 12 weeks, there was a decrease in the average abdominal circumference of menopausal women by $1 \mathrm{~cm}$, while in the control group who got the older version of elderly gymnastics, there was an average increase in abdominal circumference by $0.3 \mathrm{~cm}$.

The results of other studies showed a decrease in the average size of abdominal circumference in the elderly (men and women) by $3 \mathrm{~cm}$ after being performed elderly gymnastics for six months once a week [21]. Elderly gymnastics performed regularly can increase the burning of subcutaneous fat due to the need for energy needed in the elderly increased. Elderly gymnastics with a mild intensity aimed at reducing the risk in the elderly will provide a gradual and sluggish decrease in body fat mass in menopausal women, not quickly. This decrease in waist circumference also indirectly lowers the risk of metabolic disease in the elderly.

e. Triglycerides

Many studies have shown a link between postmenopausal status and elevated levels of total cholesterol and low-density lipoprotein cholesterol. Changes in hormone levels associated with serum lipid profile in the form of increased LDL will increase the risk of heart disease in menopause. Changes in hormones during menopause such as low plasma estrogen and high luteinization levels and follicle- 
stimulating hormones give a significant effect on plasma lipid metabolism and lipoproteins. Serum lipid profile is measured for cardiovascular risk prediction with its basic parameters total cholesterol, HDL cholesterol, LDL cholesterol, and Triglycerides. Menopause causes changes in lipid profile by lowering HDL levels, increasing levels of TC, TG, LDL-C, and VLDL-C, thereby increasing the risk of CVD. But ethnic and geographical variations also affect lipid profiles in postmenopausal women [22].

The average triglyceride levels in the treatment group were $136.4 \mathrm{mg} / \mathrm{dl}$ and in the control group was $155.28 \mathrm{mg} / \mathrm{dl}$. After an elderly gymnastics modification for 12 weeks in the treatment group, the average triglyceride level decreased by 134 $\mathrm{mg} / \mathrm{dl}$. In the control group, triglyceride levels increased by $162.34 \mathrm{mg} / \mathrm{dl}$. The results showed that modified elderly gymnastics resulted in reduced triglyceride levels after 12 weeks of treatment. Triglycerides are the main fats in the body that come from food or excess calories due to overeating. The increase or decrease in triglyceride levels is not only related to elderly gymnastics but also closely related to diet and daily activities.

\section{CONCLUSION}

Elderly gymnastics modifications in menopausal women can decrease body fat mass (\% body total fat, abdominal fat thickness, and abdominal circumference size) gradually and occur after 8 weeks of intervention. Gymnastics is also effective in decreasing triglyceride levels after 12 weeks of intervention in menopausal women. Modified elderly gymnastics and older versions of elderly gymnastics can maintain the stability of visceral fat percentage in menopausal women.

\section{REFERENCES}

[1] WHO. (2020). World health statistics 2020: monitoring health for the SDGs, sustainable development goals. Retrieved from https://apps.who.int/iris/bitstream/handle/10665/332070/9789240005105-eng.pdf

[2] Reinders, I., Visser, M., \& Schaap, L. (2017). Body weight and body composition in old age and their relationship with frailty. Current Opinion in Clinical Nutrition \& Metabolic Care, 20(1), 11-15.

[3] Samper-Ternent, R., \& Al Snih, S. (2012). Obesity in older adults: epidemiology and implications for disability and disease. Reviews in clinical gerontology, 22(1), 10-34.

[4] Gupta, R., Sawhney, P., Ambasta, R., \& Kumar, P. (2015). Obesity and neurodegeneration. Adv Obes Weight Manag Control, 2(5), 96-101.

[5] Davis, S. R., Castelo-Branco, C., Chedraui, P., Lumsden, M. A., Nappi, R. E., Shah, D. V. P. (2012). Understanding weight gain at menopause. Climacteric, 15, 419-429.

[6] Lizcano, F., \& Guzmán, G. (2014). Estrogen deficiency and the origin of obesity during menopause. BioMed research international, 2014.

[7] Joo, J. K., \& Lee, K. S. (2014). Pharmacotherapy for obesity. Journal of menopausal 
medicine, 20(3), 90-96.

[8] Sapulete, I. M. (2016). Pengaruh senam lansia terhadap kadar kolesterol total pada lansia di BPLU Senja Cerah Manado.

[9] Francis, P. (2014). Physical activities in elderly: benefits and barriers. Retrieved from https://www.theseus.fi/bitstream/handle/10024/77087/Francis _Purity.pdf?sequence=1

[10] Refat, S., Sibaii, H., \& El-Sham, K. A. (2019). Physiological Effects of Fat Loss.

[11] Noh, H., Lee, H., Kim, S., Joo, J., Suh, D., Kim, K., \& Lee, K. (2019). The Efficacy of Body Mass Index and Total Body Fat Percent in Diagnosis Obesity according to Menopausal Status. Journal of menopausal medicine, 25(1), 55-62.

[12] Cevenini, E., Monti, D., \& Franceschi, C. (2013). Inflamm-ageing. Current Opinion in Clinical Nutrition $\mathcal{E}$ Metabolic Care, 16(1), 14-20.

[13] Lorenzini, A., Santoro, A., \& Monti, D. (2020). EDITORIAL Adipose Tissue: Which Role in Aging and Longevity?. Frontiers in Endocrinology, 11, 583.

[14] Ballin, M., Lundberg, E., Sörlén, N., Nordström, P., Hult, A., \& Nordström, A. (2019). Effects of Interval Training on Visceral Adipose Tissue in Centrally Obese 70-Year-Old Individuals: A Randomized Controlled Trial. Journal of the American Geriatrics Society, 67(8), 1625-1631.

[15] Spadaccini, D., Perna, S., Peroni, G., D'Antona, G., Iannello, G., Faragli, A., ... \& Rondanelli, M. (2020). DXA-Derived Visceral Adipose Tissue (VAT) in Elderly: Percentiles of Reference for Gender and Association with Metabolic Outcomes. Life, 10(9), 1-15.

[16] Numao, S., Katayama, Y., Nakata, Y., Matsuo, T., Nakagaichi, M., \& Tanaka, K. (2020). Association of abdominal fat with metabolic syndrome components in overweight women: effect of menopausal status. Journal of physiological anthropology, 39, 1-8.

[17] Sofa, I. M. (2018). Kejadian obesitas, obesitas sentral, dan kelebihan lemak viseral pada lansia wanita. Amerta Nutrition, 2(3), 228-236.

[18] Wilmore, J. H., \& Costill, D. L. (1994). Physiology of Sport and Exercise. Human Kinetics Publishers.

[19] Lira, S. C., Muro, A. M. F., \& Ortiz, S. R. (2015). Relation of skinfold thickness and visceral fat with the endothelial function in Mexican postmenopausal women. Przeglad menopauzalny= Menopause review, 14(2), 90-96.

[20] Hung, C. Y., Chang, C. W., Chen, C. J., Chang, C. W., Cheng, H. Y., \& Chen, M. J. (2018). Sonographic Measurement of Visceral Fat and Prediction of Metabolic Syndrome in the Elderly. International Journal of Gerontology, 12(4), 331-335.

[21] Purnawati, S., Adiatmika, I. P. G., Muliarta, M., Sundari, R., \& Dinata, K. (2016). Efek Pemberian Senam Lansia Terhadap Perubahan Lingkar Pinggang Lansia Desa Jegu Tabanan. Sport and Fitness Journal, 4(2).

[22] Anyigor-Ogah, C, Onwe, P. E., Obimma, J., Ottah-Umahi, G., \& Okorocha, A. E, (2015). Menopause and serum Lipid Profile a Review. Journal of Medical and Dental Science Research, 2(11), 16-25. 